\title{
Radiofrequency for Treatment of Refractory Epistaxis in Hereditary Hemorrhagic Telangiectasia
}

\section{Radiofrequência no Tratamento da Epistaxis Refractária na Telangiectasia Hemorrágica Hereditária}

\author{
Mariana DONATO $\otimes^{1}$, João PIMENTEL ${ }^{1}$, Rui CABRAL ${ }^{1}$, Pedro ESCADA ${ }^{1,2}$ \\ Acta Med Port 2018 Jan;31(1):63-66 - https://doi.org/10.20344/amp.8802
}

\begin{abstract}
Hereditary hemorrhagic telangiectasia is a rare multi-systemic autosomal dominant disorder characterized by dysplasia of the vascular connective tissue and recurrent bleeding tendency. Epistaxis is the most common and earliest symptom. It is usually mild to moderate, however, in some patients it can be severe with significant interference in quality of life. We report a case of a patient with hereditary hemorrhagic telangiectasia, in which an episode of refractory epistaxis was treated with radiofrequency and fibrin sealant. Control of acute bleeding and elimination of telangiectasia was possible with this technique. After six months follow-up, there was no epistaxis recurrence. Various treatments for epistaxis in this disease have been described in the literature, but there is no consensus about the gold-standard procedure. Radiofrequency ablation of telangiectasia is a recent technique that has shown to be safe, effective and well tolerated, even in patients who underwent other previous treatments.
\end{abstract}

Keywords: Epistaxis; Radiofrequency; Telangiectasia, Hereditary Hemorrhagic

\section{RESUMO}

A telangiectasia hemorrágica hereditária é uma doença autossómica dominante, multissistémica e rara, caracterizada pela displasia do tecido conectivo vascular com tendência à hemorragia recorrente. O sintoma mais comum e precoce é a epistaxis. Habitualmente é ligeira a moderada, no entanto, em alguns doentes, pode ser severa com interferência significativa na sua qualidade de vida. É reportado o caso de um doente com telangiectasia hemorrágica hereditária, em que um episódio de epistaxis refractária foi tratado com radiofrequência e um quelante de fibrina. Com esta técnica foi conseguido não só o controlo da hemorragia activa, mas também a eliminação das telangiectasias. Após seis meses de seguimento, não houve recorrência da epistaxis. Há vários tratamentos descritos na literatura para a epistaxis nesta doença, não havendo no entanto, consenso acerca do gold standard. A ablação com radiofrequência das telangiectasias é uma técnica recente que se tem mostrado segura, eficaz e bem tolerada, mesmo em doentes submetidos previamente a outros tratamentos.

Palavras-chave: Epistaxe; Radiofrequência; Telangiectasia Hemorrágica Hereditária

\section{INTRODUCTION}

Hereditary hemorrhagic telangiectasia $(\mathrm{HHT})$, also known as Rendu-Osler-Weber disease, is a rare multisystemic autosomal dominant disorder characterized by vascular connective tissue dysplasia, leading to thin, fragile and vulnerable-to-injury vessels with consequent rupture and hemorrhage. It is a disease with equal gender prevalence and has its highest prevalence in Curacao Island (Netherlands Antilles) in the southern Caribbean. ${ }^{1-8}$

The Curacao criteria establish a definite diagnosis of HHT when three of the following four manifestations are found: recurrent epistaxis, mucocutaneous telangiectasia, arteriovenous malformations and positive family history. $2,4,5$

Epistaxis is the mostcommonand earliestsymptom. . $^{1,4-6,9-11}$ It is usually mild to moderate, however, in some patients it can be severe leading to significant impact on quality of life and requiring regular blood transfusions. ${ }^{14,10,11}$

Although there is no definitive treatment, various treatments for epistaxis in HHT have been proposed. . $-4,7,10,11^{-1}$

This paper reports a case of a patient with $\mathrm{HHT}$, in which an episode of refractory epistaxis was successfully treated with radiofrequency.

\section{CASE REPORT}

A 61-year-old male from Curacao Island, with HHT was transferred from Hospital de Santo Espírito in Terceira Island (Azores, Portugal) to our Otolaryngology (ENT) department. He had an episode of epistaxis from the left nasal cavity that was refractory to nasal packing.

The disease was diagnosed several years before (Fig. 1). The patient had chronic iron deficiency anemia, type 2 diabetes mellitus and was being treated with tranexamic acid, ferrous sulfate and metformin. He had a personal history of several episodes of epistaxis in the left nasal cavity requiring transfusional support, and had been subjected to several telangiectasia ablation sessions with Nd:YAG laser (Fig. 2). The patient did not report recent epistaxis from the right side. The right nasal vestibule was very stenotic due to synechiae giving the appearance of Young's postprocedure (Fig. 3). The last treatment had been performed two months before in the Netherlands, again with ablation of left nasal telangiectasia with Nd:YAG laser.

The acute and severe hemorrhage occurred during a flight from the Netherlands to his native island, forcing an emergency landing in Terceira Island. He had his left nasal cavity packed with non-laminated merocel ${ }^{\circledR}$ and received a

1. Otolaryngology Department. Hospital de Egas Moniz. Centro Hospitalar Lisboa Ocidental. Lisboa. Portugal.

2. NOVA Medical School. Faculdade de Ciências Médicas. Universidade Nova. Lisboa. Portugal.

$\bowtie$ Autor correspondente: Mariana Donato. marianamldonato@gmail.com

Recebido: 06 de fevereiro de 2017 - Aceite: 06 de julho de 2017 | Copyright @ Ordem dos Médicos 2018 


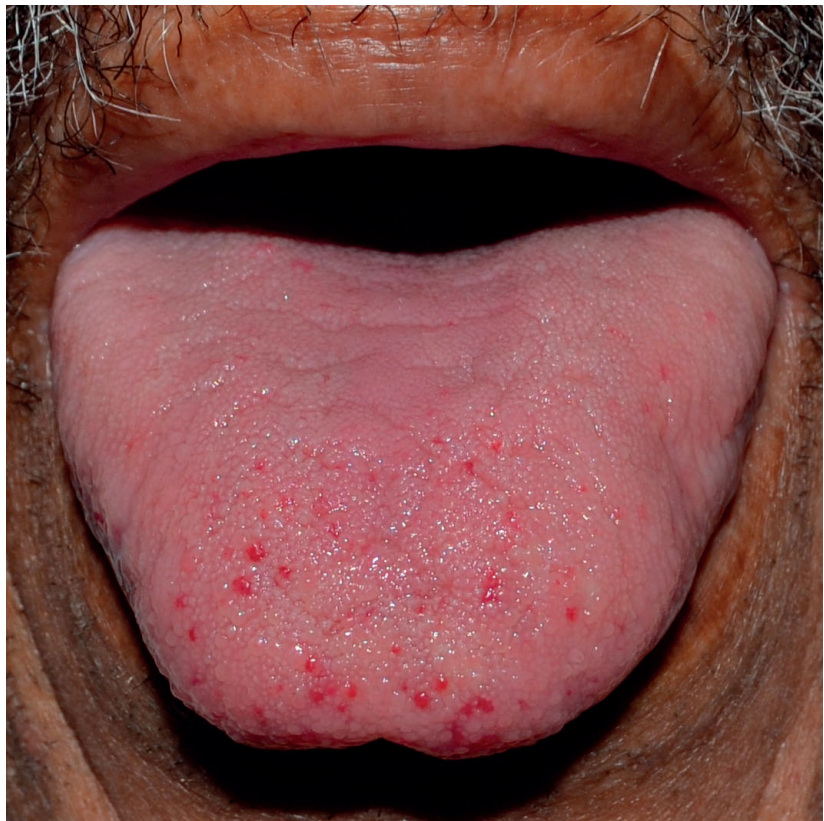

Figure 1 - Mucocutaneous telangiectasia

total of 12 blood transfusions. Due to the refractory epistaxis the patient was transferred to Lisbon.

Upon arrival to our institution, the patient was hemodynamically stable and removal of the nasal packing was scheduled for the next day under general anesthesia. After removal of the nasal packing, epistaxis recurred immediately. Two types of bleeding were observed: an arterial/pulsed vessel arising from the Kiesselbach plexus and a more posterior venous bleeding.

The bleeding was controlled under endonasal endoscopic approach using radiofrequency - Evac70 ${ }^{\circledR}$ Ultra Xtra in coagulation mode (Fig. 4). By the end of the procedure, $\mathrm{TachoSi}^{\circledR}$ was placed on the septal and external walls of the nasal cavity (Fig. 5). The patient left the operating room without nasal packing.

During his admission, he received a single dose of ferric carboxymaltose and cobamamide and there was no need

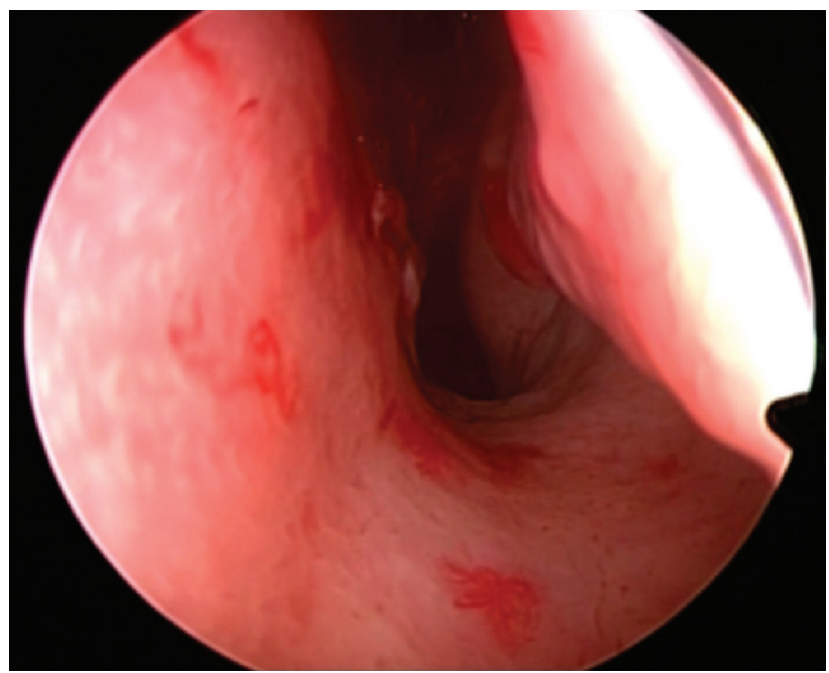

Figure 2 - Telangiectasia from posterior part of the left nasal cavity for blood transfusions. The patient was discharged after two weeks and flew back home after two more weeks without epistaxis recurrence.

Six months after surgery the patient was contacted by telephone and stated that he had no epistaxis episodes since then.

\section{DISCUSSION}

There are various therapeutic options for epistaxis in $\mathrm{HHT}$, with no consensus about the gold-standard procedure. . $-4,7,10,11^{-1}$

The most widely used treatments can be divided into four major groups: elimination of telangiectasia, reduction of blood flow, reduction of trauma and improvement of protection. ${ }^{9}$

The first group includes laser ablation, argon plasma coagulation and radiofrequency. ${ }^{9}$

Laser coagulation is a non-invasive procedure and there are different forms of laser photocoagulation including the argon, KTP and Nd:YAG laser. ${ }^{2,4,9,11}$ Several papers show the efficiency of this treatment in HHT patients with mild to moderate epistaxis, with a reduction of the number of episodes for an average period of 6 months. ${ }^{4,9,10}$ Patients with more severe forms of the disease, requiring multiple blood transfusions, seem to benefit less from this treatment. ${ }^{9}$ There are few studies comparing the effectiveness of different types of laser, however the efficacy of Nd:YAG, KTP and argon lasers seems to be similar, with a higher risk of septal perforation with Nd:YAG. 1,4,9

Argon plasma coagulation is a non-contact form of monopolar electrical cautery that is based on the principle that tissues with high electrical conductivity (such as blood vessels) will be preferentially coagulated. ${ }^{2,7,9}$ This system has been presented as an alternative to the Nd:YAG laser, as coagulation and dissection of tissue are limited to a depth of 1 to $2 \mathrm{~mm}$. The risk of tissue damage and septal perforation are lower., $2,7,9$

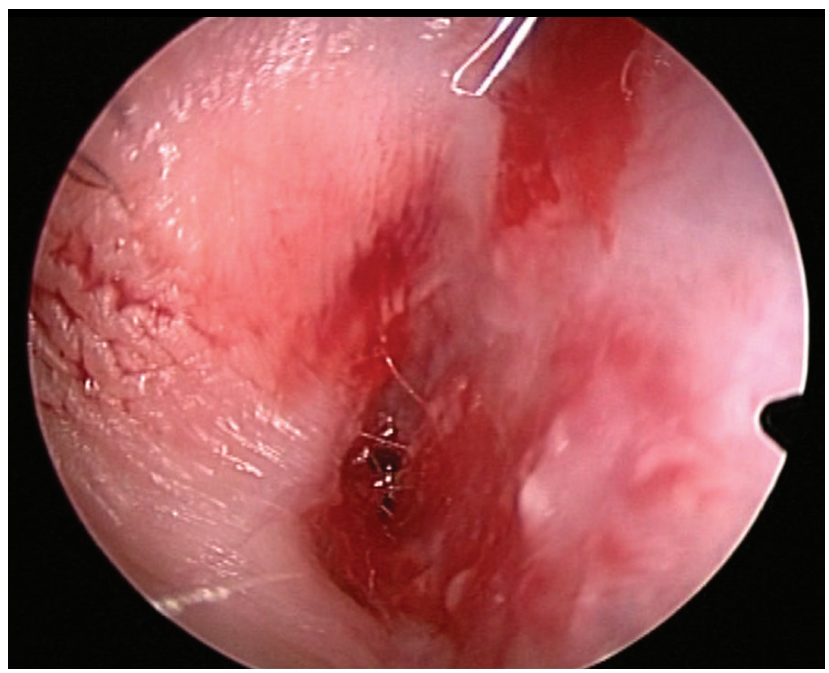

Figure 3 - The right nasal vestibule was very stenotic due to synechiae giving the appearance of Young's post-procedure 


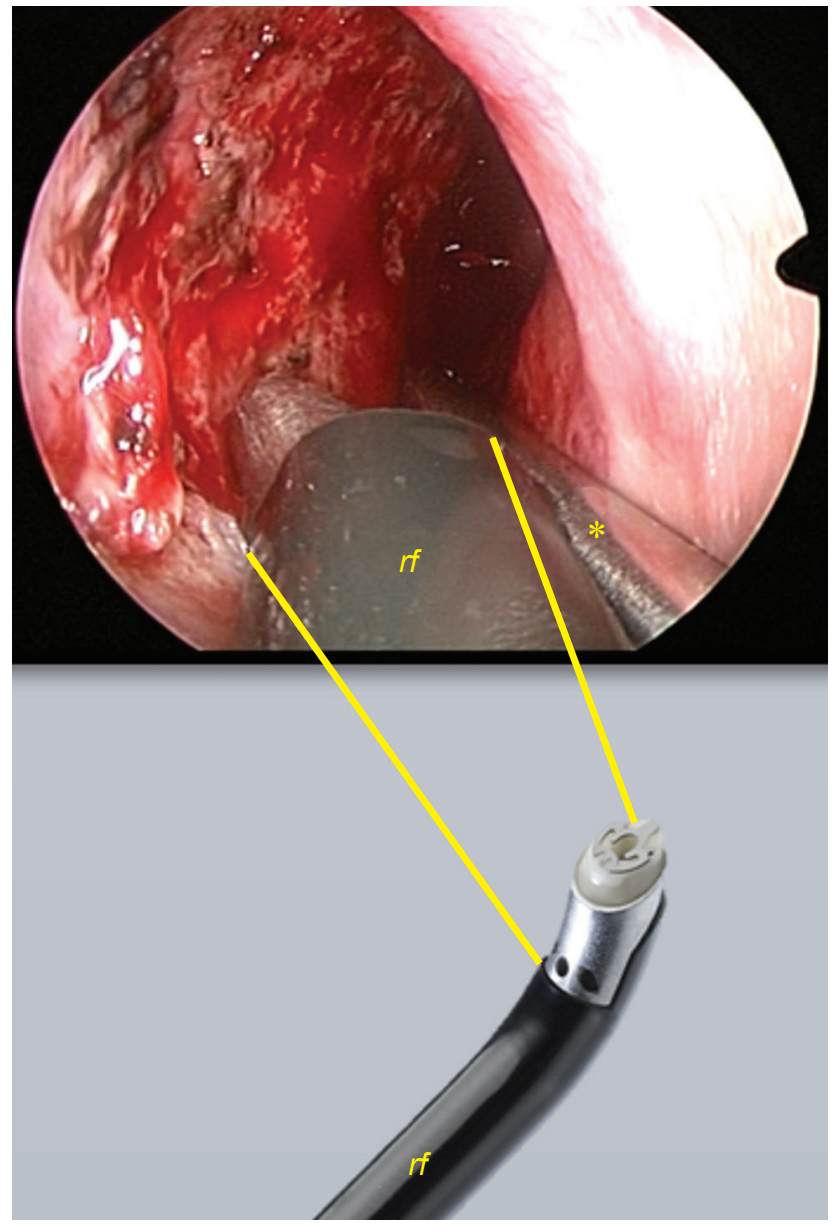

Figure 4 - The bleeding had been controlled using radiofrequency - Evac $70^{\circledR}$ Ultra Xtra in coagulation mode. Suction $\left(^{*}\right)$ was needed simultaneously because of the bleeding debt.

Radiofrequency treatment is a recent method of achieving sclerosis of nasal telangiectasia. ${ }^{3,11,12}$ In this case report, the surgical procedure was performed under general anesthetic with an endonasal endoscopic approach. The radiofrequency wand $\left(\right.$ Evac $70^{\circledR}$ Ultra Xtra in coagulation mode) was applied directly on the nasal mucosa, vaporizing and controlling the bleeding areas. In the literature, this procedure has been described as a preventive treatment: the radiofrequency energy is applied to all visible HHT plaques on both sides of the septum and turbinates until no further telagiectasias are seen. ${ }^{8}$ In the presented case, radiofrequency was also found to be an effective method of controlling acute bleeding. Unlike laser or the standard electrocautery devices, radiofrequency works at low temperatures (between $40^{\circ} \mathrm{C}-70^{\circ} \mathrm{C}$ ), thereby causing less thermal injury to adjacent tissues and minimizing the risk of septal perforation. ${ }^{3,8,12}$ Theoretically, it also reduces the amount of crusting and scarring. ${ }^{12}$ The use of radiofrequency for HHT epistaxis is a much more conservative procedure than laser and can be safely repeated without significant complications. . $^{3,8,11,12}$

The group of treatments that decrease the blood flow includes nasal packing, angiographic embolization and

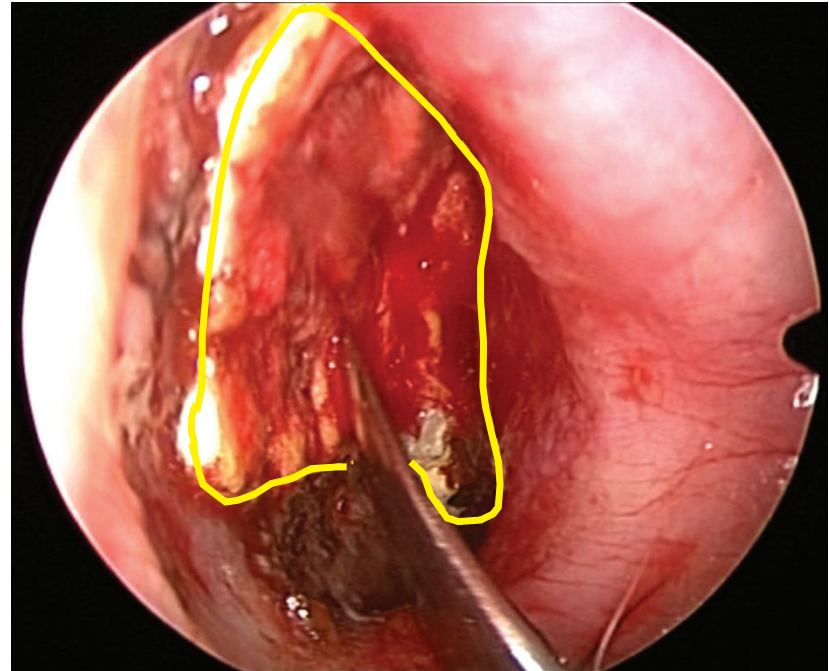

Figure 5 - By the end of the procedure, TachoSi ${ }^{\circledR}$ was placed on the septal and external walls of the left nasal cavity

arterial ligation. ${ }^{9}$ We also include in this group the topical hemostats.

Nasal packing is useful to control acute bleeding. ${ }^{9}$ The main advantage is that it can be applied by the patient, overcoming critical situations where there is no immediate access to medical care. However, in $\mathrm{HHT}$, the mucosal trauma caused by the placement of the pack often leads to a recurrence of bleeding once removed. ${ }^{9}$ So it is recommended to use absorbable products whenever possible.

Angiographic embolization of the sphenopalatine artery should only be used in emergency situations or when standard surgical approaches fail. ${ }^{1,9}$ This procedure has a high complication rate and is contraindicated in anterior ethmoidal artery bleeding. ${ }^{7,9}$ Furthermore, HHT patients require more frequent re-embolizations, since they often present an anterior epistaxis of the Kiesselbach's plexus (in contrast with refractory epistaxis due to other causes, which most frequently originates from branches of the sphenopalatine artery). ${ }^{11}$

The ligation of vessels of the external carotid artery territory exhibits good results, but only for a short period of time (since new dysplastic vessels can regenerated) and has a high complication rate..$^{7,9}$

TachoSil $^{\circledR}$ is a fibrin sealant that has a hemostatic effect by triggering the last stage of the coagulation cascade. ${ }^{13}$ It is known that the association of radiofrequency with a fibrin-based hemostat is effective in controlling bleeding in the liver, spleen and urologic surgery ${ }^{14,15}$ and it also seems to provide excellent results in controlling acute epistaxis in HHT patients.

The reduction of trauma group includes the Young's procedure and application of nasal ointments. ${ }^{9}$

Young's procedure (closure of the anterior nares) is a radical and effective procedure for life-threatening or transfusion-dependent epistaxis, when other treatments have failed. ${ }^{11}$ The technique involves raising skin and 
mucosal flaps that are closed in a double-layered fashion, allowing a complete closure of the nostrils. ${ }^{11}$ The elimination of airflow trauma through the nasal cavity results in complete remission of the epistaxis. This technique also results in a complete nasal obstruction, requiring an obligatory mouthbreathing and hyposmia. These symptoms are usually not well tolerated by patients. ${ }^{9-12}$

Most of the nasal ointments used have a lipid base, as the effect appears to be longer than aqueous base preparations. They turn the nasal cavity into a moist chamber, which has a positive impact on the frequency of epistaxis. ${ }^{1,9}$

The improvement of protection group includes septodermoplasty and sexual hormone therapy. ${ }^{9}$

Septodermoplasty (Saunders' procedure), involves the replacement of the anterior part of the septal mucosa (with preservation of the underlying perichondrium) by a free skin graft. ${ }^{1,9,11,12}$ Although this method allows an initial symptomatic improvement, the effect is lost throughout the years due to the contraction and revascularization of the graft with formation of new telangiectasia. ${ }^{1,9-11}$ Septodermoplasty also leads to the loss of the normal mucociliary function, which results in chronic crusting and halitosis. ${ }^{11,12}$

Estrogen ointments have been used in mild epistaxis, without significant systemic side-effects. Its topical application induces a squamous metaplasia of the respiratory epithelium, leading to a better protection of the underlying vessels. ${ }^{11}$ However, the effectiveness of this type of ointment has not been established. ${ }^{9,11}$ The use of systemic estrogen allows for a reduction of the frequency and severity of bleeding, but its side-effects make it only tolerable in female patients. ${ }^{1}$

\section{CONCLUSION}

Radiofrequency ablation of the telangiectasia is a recent technique that has shown to be safe, effective and well tolerated for controlling epistaxis in HHT patients.

It can be applied in cases of acute haemorrhage with ablation of the bleeding vessels and it seems to control the epistaxis episodes in the long term by periodic and selective ablation of the telangiectasia.

There are no guidelines or consensus about the goldstandard treatment for epistaxis in HHT patients. Among the various therapies available which are here systematized, radiofrequency associated with fibrin-based hemostat appears to be a valid option.

\section{ACKNOWLEDGMENTS}

We would like to acknowledge João Martins for making the diagnose and for referring the patient to our institution.

\section{PROTECTION OF HUMANS AND ANIMALS}

The authors declare that the procedures were followed according to the regulations established by the Clinical Research and Ethics Committee and to the Helsinki Declaration of the World Medical Association.

\section{DATA CONFIDENTIALITY}

The authors declare having followed the protocols in use at their working center regarding patients' data publication. Informed consent was duly obtained from the patient.

\section{CONFLICTS OF INTEREST}

All authors report no conflict of interest.

\section{FUNDING SOURCES}

This research received no specific grant from any funding agency in the public, commercial, or not-for-profit sectors.

Rhinol Allergy. 2015;29:226-7

9. Geisthoff UW, Fiorella ML, Fiorella R. Treatment of recurrent epistaxis in HHT. Curr Pharm Des. 2006;12:1237-42.

10. Hitchings AE, Lennox PA, Lund VJ, Howard DJ. The effect of treatment for epistaxis secondary to hereditary hemorrhagic telangiectasia. Am J Rhinol. 2005;19:75-8.

11. Sautter NB, Smith TL. Hereditary hemorrhagic telangiectasia-related epistaxis: innovations in understanding and management. Int Forum Allergy Rhinol. 2012;2:422-31.

12. Joshi H, Woodworth BA, Carney AS. Coblation for epistaxis management in patients with hereditary haemorrhagic telangiectasia: a multicentre case series. J Laryngol Otol. 2011;125:1176-80.

13. Rickenbacher A, Breitenstein S, Lesurtel M, Frilling A. Efficacy of TachoSil a fibrin-based haemostat in different fields of surgery-a systematic review. Expert Opin Biol Ther. 2009;9:897-907.

14. Gumbs AA, Bouhanna P, Bar-Zakai B, Briennon X, Gayet B. Laparoscopic partial splenectomy using radiofrequency ablation. J Laparoendosc Adv Surg Tech A. 2008;18:611-3.

15. Tan YH, Young MD, L'Esperance JO, Preminger GM, Albala DM. Hand-assisted laparoscopic partial nephrectomy without hilar vascular clamping using a saline-cooled, high-density monopolar radiofrequency device. J Endourol. 2004;18:883-7. 